\title{
VALORES DE JOVENS UNIVERSITÁRIOS BRASILEIROS E CHINESES: UM ESTUDO SOCIOLÓGICO COMPARADO
}

\author{
Values of Brazilian and Chinese University Srudents: a comparative \\ sociological study
}

DWYER, Tom; ZEN, Eduardo Luiz; WELLER, Wivian; SHUGUANG, Jiu; KAIYUAN, Guo. Jovens universitários em um mundo em transformação: uma pesquisa sino-brasileira. Brasília: Ipea; Pequim: SSAP, 2016. 3II p.

Vanessa Silveira de Brito'

O livro foi baseado numa pesquisa do tipo levantamento de dados (survey) sobre os valores, estilos de vida e perspectivas de jovens universitários no Brasil e na China. É fruto de um estudo comparado que demonstra o resultado da cooperação entre os dois países e é de extrema relevância por seu pioneirismo - trata-se da primeira pesquisa sinobrasileira em ciências sociais.

A obra foi viabilizada pelo empenho de cientistas sociais que promoveram ações articuladas nos dois países e foi realizada nas capitais e nos principais polos financeiros, comerciais e industriais do Brasil e da China. Os questionários foram aplicados em jovens universitários brasileiros e chineses, na faixa etária compreendida entre 18 e 24 anos de idade. Os dados foram produzidos em quatro regiões: Shangai, Pequim, São Paulo e Brasília, configurando o que um dos colaboradores denomina de "retrato comparativo do cotidiano e das origens sociais dos universitários brasileiros e chineses".

O livro, publicado simultaneamente em português pelo Instituto de Pesquisa Aplicada (IPEA) e em chinês pela Social Sciences Academic Press (SSAP) - editora vinculada à Academia Chinesa de Ciências Sociais (CASS) se apresenta como uma coletânea de artigos que refletem não apenas o rigor

\footnotetext{
1 Mestre em Educação, Comunicação e Cultura pela Universidade do Estado do Rio de Janeiro. Email: vanessabrito482@gmail.com
} 
Valores de Jovens Universitários Brasileiros e Chineses | Vanessa Silveira de Brito

das equipes brasileira e chinesa no tratamento e análise dos dados coletados, mas também uma preocupação com o leitor interessado na temática.

Além dos capítulos referentes aos resultados do levantamento realizado, os pesquisadores de ambas as equipes dedicaram os capítulos iniciais da obra à descrição do cenário atual e da perspectiva histórica no que diz respeito às mudanças ocorridas no âmbito da educação superior de seus respectivos países.

O artigo Ensino Superior da China, de Gao Yingshuang, abre o livro e aborda as reformas educacionais do ensino superior no país oriental em questão desde o ano de 1998. Neste capítulo, o autor demonstra que as reformas no ensino superior chinês tem como finalidade o aumento do número de pessoas matriculadas nas universidades de excelência do país, criando um sistema adequado às necessidades dos indivíduos e que atenda ao projeto de crescimento social e o esperado desenvolvimento do país. Aqui, destaca-se a triade que norteia a tendência do desenvolvimento da educação superior na China: qualidade, eficiência e igualdade.

O capítulo seguinte Análise da Dinâmica Demográfica da China, escrito por Yang Jianglan e Wang Jie, apresenta uma análise cuidadosa a respeito da estrutura, da distribuição e das características da população chinesa, sendo uma base importante para a compreensão da análise dos dados acerca dos valores dos universitários chineses. O acelerado desenvolvimento econômico e social provoca mudanças na dinâmica demográfica da China, ocasionando uma redução gradativa no ritmo de crescimento populacional do país e o aumento gradativo da população idosa.

Assim como a equipe chinesa, os colaboradores brasileiros também dedicaram dois capítulos à análise do cenário da pesquisa. Clarissa Eckert Baeta Neves e Carlos Benedito Martins assinam o terceiro capítulo Ensino Superior no Brasil: uma visão abrangente, que traz um panorama da educação superior brasileira, apresentando numa perspectiva histórica as mudanças e reformas no sistema de ensino. Os autores destacam a Reforma Universitária de 1968, que veio atender a crescente demanda para o ensino superior e formalizou a pós-graduação stricto sensu (mestrado e doutorado). 
O país consolida o sistema de ensino a partir dos segmentos público e privado, abarcando uma diversidade de instituições de ensino superior públicas (federais, estaduais e municipais) e privadas (particulares, comunitárias e filantrópicas) - o que resulta num campo acadêmico marcado pela heterogeneidade. Apesar da notável expansão do ensino superior, com a ampliação do acesso e das políticas sociais de inclusão, a persistência das desigualdades sociais ainda se apresenta como um desafio, especialmente, no que tange ao ingresso e à permanência dos alunos na universidade.

O capítulo quatro, Juventude e Ensino Superior no Brasil, de Ana Maria Nogales Vasconcelos, discute os aspectos demográficos da relação entre juventude e ensino superior no Brasil, revelando dados acerca das desigualdades sociais que refletem nas desigualdades educacionais. O texto revela ainda os grupos que estariam mais vulneráveis no sentido da descontinuidade dos estudos, quer seja, jovens de renda baixa, do sexo masculino, pretos, pardos e indígenas. Assim, conclui-se que tais grupos devem ter as oportunidades de acesso ampliadas através das políticas de cotas estabelecidas para o ingresso nas instituições públicas de ensino superior. Vale ressaltar que dados semelhantes podem ser observados em diversos estudos sobre ensino superior e as politicas de ações afirmativas no contexto educacional brasileiro.

Após a contextualização da pesquisa, o livro apresenta as reflexões comparadas e artigos acerca dos valores dos jovens universitários brasileiros e chineses. A maioria dos capítulos que se seguem é assinada conjuntamente por pesquisadores brasileiros e chineses. O organizador da obra apresenta brevemente o cenário dos dois países, apontando as semelhanças decorrentes da globalização no capítulo cinco. E os artigos subsequentes trazem aspectos que enriquecem a análise das experiências de inserção nos diferentes espaços da vida social de jovens universitários brasileiros e chineses: a origem familiar, as trajetórias acadêmicas, as perspectivas de futuro, a participação política, os princípios e valores dos estudantes, dentre outros.

Nesta perspectiva, o quinto capítulo Universitários em tempos de pósindustrialismo e globalização: contribuições para o diálogo sino-brasileiro, 
Valores de Jovens Universitários Brasileiros e Chineses | Vanessa Silveira de Brito

inaugura e efetiva o diálogo sino-brasileiro. Neste artigo, Tom Dwyer, afirma que o cenário de ambos os países apresenta uma série de semelhanças. E que estas podem ser explicadas pelo fenômeno da globalização que transforma os sistemas de ensino e a divisão internacional de trabalho.

O autor afirma que os dois países se conhecem pouco, apesar de serem parceiros comerciais. Neste sentido, o comércio e a diplomacia contribuem na construção de interesses em comum e valores compartilhados e, tendo isso em vista, estabelecer um diálogo entre os dois países se torna importante do ponto de vista comercial e político. Pesquisadores chineses acreditam que o estudo acerca dos valores de universitários brasileiros e chineses pode ser um passo importante para fomentar a construção de outros diálogos e de parcerias entre os dois países.

$\mathrm{Na}$ análise realizada, observou-se que os jovens de ambos os países preocupam-se com o futuro no tocante a inserção no mercado de trabalho, especialmente, temem uma colocação inadequada à suas qualificações. Outro ponto em comum diz respeito à percepção da família como algo central na vida dos universitários.

O capítulo seis, de autoria de Wivian Weller, Chen Weidong e Lucélia de Moraes Braga Bassalo, intitulado Origem Familiar, Percursos Acadêmicos e Projetos de Estudantes Universitários Brasileiros e Chineses aparece como uma extensão do capítulo anterior, em especial, no tocante à importância da família para os jovens universitários. Os pesquisadores estabelecem uma relação entre a origem familiar, as trajetórias universitárias e as perspectivas dos estudantes. Destaca-se o nível de escolaridade e a situação profissional dos genitores dos entrevistados e a estreita relação destes aspectos com o acesso à universidade. Um número significativo de universitários pertence a famílias em que os pais possuem vínculos com maior estabilidade no mercado de trabalho, além de melhores salários. Seguindo este raciocínio, pode-se pensar ainda que este contexto colabora para que universitários brasileiros e chineses valorizem a continuidade dos estudos após a graduação.

No capítulo seguinte Os Jovens Universitários e o Trabalho: uma visão comparada entre Brasil e China, Eduardo Luiz Zen revela que, no Brasil, os 
universitários ingressam mais cedo no mercado de trabalho e estabelecem uma dupla jornada - o que pode impactar não apenas a trajetória profissional, mas também trazer prejuízos ao desempenho acadêmico. Talvez em função disso, a transição da condição de aluno para a condição de trabalhador se mostra um tanto confusa. Em geral, nos países desenvolvidos ocorre o contrário. Contudo, na China (um país em desenvolvimento), podese observar que a passagem da universidade ao trabalho parece ser muito mais nitida.

Diante desse contexto, o artigo aponta a necessidade dos gestores governamentais brasileiros e chineses darem mais atenção às medidas pertinentes às áreas de políticas públicas de juventude, de educação e de trabalho. Aliado a isso, os gestores devem considerar as demandas por medidas que tornem mais viável a conciliação entre o ensino superior e a realidade de trabalho dos jovens universitários.

Em seguida, Guo Kaiyuan, Yang Shoujian, Chen Chen e Wang Peng assinam o oitavo artigo da coletânea, Valores de Universitários Chineses e Brasileiros Contemporâneos. Ao longo do texto, fica evidente que, tanto na China quanto no Brasil, os universitários almejam estabilidade e previsibilidade. E, na incerteza do futuro, buscam refúgio nos laços familiares. De acordo com a pesquisa realizada, os principais valores dos universitários chineses estão relacionados à liberdade, à igualdade, à ética e honestidade, à justiça e à valorização da família. Já para os jovens brasileiros, os valores apresentam a seguinte sequência: ética e honestidade, valorização da família, respeito à diversidade étnica/racial e justiça. A análise dos dados revela a diferença cultural entre os países.

No capítulo nove Sociabilidade, Percepções e Valores: uma comparação entre jovens universitários brasileiros e chineses, de Marilia Pontes Sposito, Marilena Nakano e Chen Chen, as autoras destacam as singularidades dos percursos e das experiências dos universitários chineses e brasileiros. A família aparece em diversas situações da pesquisa, por exemplo, na escolha do curso dos jovens chineses e no convivio sob o mesmo teto, no caso dos estudantes brasileiros. Fato é que, apesar da diferença no sentido da 
Valores de Jovens Universitários Brasileiros e Chineses | Vanessa Silveira de Brito

valorização, em ambos os países, o núcleo familiar apresenta uma importância significativa na trajetória dos jovens universitários.

Outro ponto que merece destaque diz respeito às desigualdades de gênero. Tanto as jovens brasileiras quanto as jovens chinesas possuem maior acesso ao sistema de ensino, em especial, ao ensino superior. Nessa perspectiva, a pesquisa indica a importância das recentes transformações no acesso ao sistema educacional, que tem assegurado a participação das mulheres. O artigo aponta ainda diferenças significativas entre brasileiros e chineses no que diz respeito à participação em associações e grupos e às práticas religiosas.

O décimo artigo A Orientação de Valores dos Universitários Chineses Contemporâneos e Suas Mudanças, de Wang Peng apresenta uma análise dos elementos que influenciam na orientação dos valores dos jovens universitários chineses - economia de mercado, reformas educacionais e diversidade de pensamentos. Considerando estes aspectos, o autor sugere a realização de medidas que sejam capazes de conduzir, de maneira pedagógica, a orientação de valores dos universitários chineses.

Em seguida, Jiu Shuguang e Guo Kaiyuan, no artigo Quadro da Participação dos Universitários Chineses na Politica e seu Aperfeiçoamento, analisam o cenário social e o sentido da participação politica dos jovens universitários chineses. Os autores descrevem cuidadosamente os meios, a postura, os princípios, as tendências e as medidas para estimular a participação dos jovens chineses no espaço político.

O artigo Valores, Origens Sociais, Estilos de Vida e Horizontes dos Universitários Chineses, de Chen Weidong, encerra o livro, trazendo uma análise dos valores atuais dos universitários chineses. Para isso, o autor trabalha com as seguintes categorias: ambiente familiar e amigos; vida universitária e planejamento após a formação; experiência no trabalho e expectativa profissional; lazer e atividades sociais dos universitários; valores que orientam os jovens chineses; consciência e participação política. $O$ capitulo apresenta uma síntese dos temas trabalhados por pesquisadores chineses ao longo da obra e realiza um debate significativo acerca dos valores dos universitários chineses. 
Cabe ressaltar que a intensidade das mudanças trazidas pelo fenômeno da globalização oferece aos jovens brasileiros e chineses uma infinidade de possibilidades acadêmicas e profissionais. Aliado a isso, a persistência das desigualdades sociais observadas em ambos os países, marcam as trajetórias juvenis e exigem dos governos o desafio da implementação e da execução de políticas públicas mais efetivas e eficazes no que se refere à juventude.

A presente obra traz um debate relevante sobre políticas públicas em perspectiva comparada, além de identificar processos sociais e valores dos jovens universitários brasileiros e chineses - o que convida o leitor à reflexão mais aprofundada sobre esses desafios. E talvez seja esta a sua contribuição mais importante, tendo em vista a urgência da construção de agendas positivas na atribulada conjuntura econômica mundial. 